\title{
Affectivity as an Underlying Factor in Anticipating an Individual's Approach to the Future
}

\author{
Robert Zaborowski ${ }^{1}$
}

Received: 6 August 2016/Accepted: 8 December 2016/Published online: 22 December 2016

(C) The Author(s) 2016. This article is published with open access at Springerlink.com

\begin{abstract}
In approaching the future, i.e. in planning projects and decision-making, the role of both affective and non-affective factors is considerable. But given that affectivity is not a homogeneous realm and that it is difficult, if not impossible, to isolate the affective and non-affective elements of a description, anticipation can be hardly described as purely affective, and, on the other, it is necessary to consider what kind or level of the hierarchical realm of affectivity is involved in the anticipation move. In the paper several distinction are made in order to elucidate the role of affectivity in anticipating a person's approach to the future (e.g. spontaneity vs. calculation, direct vs. indirect anticipation).
\end{abstract}

Keywords Affectivity $\cdot$ Anticipation $\cdot$ Emotions $\cdot$ Feelings $\cdot$ Future $\cdot$ Hierarchical realm

\section{Preliminary Distinctions}

In approaching the future, i.e. in planning projects and decision-making, the role of both affective and non-affective factors, we are often told, is considerable. We are also often told that the less affectivity-related such approaches are, the better it is for the decision made, because affectivity is spontaneous, capricious, and often runs counter to calculation and deliberation. This is why it is not a reliable basis for determining one's activity, let alone an activity projected into the future, however close or far away it is. Not everyone agrees with this, though. Some

A shorter version of the paper was presented at the 1st International Conference on Anticipation, Trento, Nov. 5-7, 2015.

Robert Zaborowski

thymos2001@yahoo.fr

$1 \quad$ University of Warmia and Mazury, Olsztyn, Poland 
phenomenologists claim that there are values or features of the world that can be grasped only or better by means of affectivity. For Heidegger:

[o]nly something which is in the state-of-mind of fearing (or fearlessness) can discover that what is environmentally ready-to-hand is threatening. [...] Pure beholding, even if it were to penetrate to the innermost core of the Being of something present-at-hand, could never discover anything like that which is threatening (Heidegger 1962, 176-177).

Others remind us of Pascal's dictum: "[t]he heart has its reasons, which reason does not know" (Pascal 1958, 78). Finally, some others, Aristotle in particular, claim that both thinking and feeling can go better and worse depending, respectively, on virtue and wisdom: if virtuous, i.e. with affectivity well disposed, a person will act well in a situation when there is no time to make a calculation or deliberate about a solution. If wise, she will act well in all other circumstances. But if her affectivity has no measure, if it is too weak or too strong for example, or she is unwise, she will act badly and then, respectively, her affectivity or her thinking will be to blame. ${ }^{1}$

Two remarks are pertinent here. The first concerns the intricacy of affectivity. Broadly speaking, what is valid for, say, sensible feelings may not work for spiritual feelings. Affectivity is not a homogeneous realm. Many want to consider it as such. But since for some it is bodily and for others mental, for some passive and for others active, for some rational and for others irrational, and similarly regarding other features, ${ }^{2}$ and since on both sides we have brilliant minds supporting their theses, we may prefer to take all these characteristics into account. This account will be fuller, yet, at the same time, more difficult to draw. Taken as heterogeneous affectivity is less reductionist and richer, but requires more time and effort to be set out. Such attempts have been already undertaken and, for now, I limit myself to suggesting that, if such heterogeneous and hierarchically construed models are acceptable, ${ }^{3}$ not all levels or kinds of affectivity contribute equally or are not equally efficient in anticipating an individual's approach to the future. For instance,

\footnotetext{
${ }^{1}$ See Aristotle (1934, 1117a): "When however things do not turn out as they expect, the merely sanguine run away, whereas the mark of the courageous man, as we have seen, is to endure things that are terrible to a human being and that seem so to him, because it is noble to do so and base not to do so. Hence it is thought a sign of still greater courage to be fearless and undismayed in sudden alarms than in dangers that were foreseen. Bravery in unforeseen danger springs more from character, as there is less time for preparation; one might resolve to face a danger one can foresee, from calculation and on principle, but only a fixed disposition of Courage will enable one to face sudden peril'.".

${ }^{2}$ For instance: is affectivity useful or harmful? Both answers are given and this is fine as long as the affectivity is rich and its variety is related to a number of factors as well as to the structure of a particular affective act. Similarly, R. Poli expressed the view to me that "[i]n many cases, anticipations gives us a plus, but there also are pathologies of anticipation. Consider the following: I define anticipations as based on two components: a forward looking attitude (shortly, a model) and the actions I take in the present as a consequence of the model's forecasts. So far so good, but the model can be wrong, or inadequate, or in need to be updated, etc. etc" (personal communication, 'per nuntium electronicum', May 2, 2016). The same is valid for emotions; see e.g. Lyons (1980, 188-192): "Emotions as organising or disruptive of behaviour" \& Ch. 13: "Blaming the emotions".

${ }^{3}$ As shown by Zaborowski (2015) a paradigmatically hierarchical approach to affectivity is that of Max Scheler and also of Plato.
} 
a "person might project his fantasy of an ideal woman onto a woman who possesses few if any of his characteristics", in which case "love [...] can only lead to tragic consequences". Or, to take a particular example, "Padre Kolbe took the place of a man in a group destined to be starved to death in a concentration camp, out of love". In my view, unless we discredit either of these views as representing love or viewing love as a contradictory phenomenon, we have merely different cases of the same genus (or class) within which we need to distinguish different species (or genera). And this is what hierarchical approaches to affectivity offer.

A second remark concerns the issue of how to define, or rather, I think, how to separate emotional and rational conditions. In many cases it is probably impossible to isolate the affective and non-affective elements of a description. Take the following example: Chris Norman was one of four who saved themselves and others on an Amsterdam-Paris Thalys train on August 21st, 2015 during a terrorist attack. It has been reported that:

[...] [a]t first he wasn't sure what to do. [...] Right after the attack, he called his wife, Martine Leonardy, and told her he had a choice to either sit and get shot or get angry and do something. He chose to get angry. [...] Norman said that when he first saw the gunman, his initial instinct was to duck down in his seat [...] But then he heard Skarlatos telling the other men to "get him." Stone jumped up and ran forward, tackling the gunman. Alek Skarlatos and Anthony Sadler followed. Norman quickly joined them, helping wrestle the gunman to the ground and get him under control. [...] In interviews, Norman has been very humble about his role in subduing the suspect. He said that he was acting purely on survival instincts and had thought that since he was going to die anyway, he'd rather die doing something instead of hiding in a corner and being shot $[\ldots]$. $^{5}$

It turns out that Norman (1) "wasn't sure what to do", and (2) that he acted out of "survival instincts", but (3) had a choice between two options: either "he had a choice to either sit and get shot or get angry and do something". Or, even more expressly, he "had thought" about his having two options, namely: that he was "going to die anyway" or that he could do "something instead of hiding in a corner and being shot". Was Norman anticipating his action affectively or non-affectively, or both? Of course, one can argue that Norman's report is a second-hand report or that even if it were first-hand, it might not be reliable: Norman says what he thinks but he may be wrong in thinking what he says or not fully aware of how and why he acted, since he could hardly have been acting out of instinct while thinking about which option to take. Or maybe Aristotle is better at grasping this, since if, according to Aristotelian perspective, Norman acted "in sudden alarm [rather] than in dangers that were foreseen", the way he acted proves he has "a fixed disposition of Courage", unless one admits that there was enough time for him to ponder or a

\footnotetext{
4 Both examples are borrowed from Lyons (1980), respectively, $199 \& 175$.

5 See http://heavy.com/news/2015/08/chris-norman-belgium-france-paris-terrorist-train-attack-gunmanhero-morocco-skarlatos-anthony-sadler-video-photos-injured-medal-british-consultant/, retrieved on Apr. $16,2016$.
} 
high enough pondering speed to credit him with wisdom rather than virtue (this is doubtful given that he did not, it seems to me, have enough data to know the result of his action).

This shows the difficulty of analysing and isolating several factors or their aspects, and this is why in what follows a divide between affective and nonaffective anticipation is, to a great extent, provisional. Therefore, affective and nonaffective mean, respectively, predominantly affective and predominantly nonaffective, rather than exclusively and purely affective and exclusively and purely non-affective. ${ }^{6}$

To sum up: on the one hand, in anticipation we hardly have a purely affective factor, and, on the other, it is useful to consider what kind or level of the hierarchical realm of affectivity this factor belongs to. For a leading theoretician in this field, "[a]n anticipatory system is a system containing a predictive model of itself and/or its environment, which allows it to change state at an instant in accord with the model's predictions pertaining to a later instant" (Rosen 1985, 341). ${ }^{7}$ As such this neither includes nor excludes anything of an affective kind, and hence this definition neither supports nor contradicts what I set forward.

\section{Crucial Distinctions}

Let us then not consider what kind of affectivity is responsible for what kind of decision, but rather focus on an example of a mainly (not purely but only predominantly) affectively anticipated decision. This is where the issue starts and, I am afraid, where it stops as soon as it has started, since when I look for such an example I have trouble finding one.

What it can be? Say I decide to build a house. But do I not have to add several qualifications? In doing so I am not motivated by a need for a house for myself, I do not build it out of need for a salary, I am not an enthusiast of building houses and do not want to invest my money in a house, and nor do I build it out of philanthropy for people who have recently lost their homes. These are all cases of being motivated affectively. Let us admit that I undertake this task for nothing. But is this at all thinkable? Hardly, but we need to posit this possibility in order to imagine a motivation affectivity-disconnected, all others being affectivity-related to a larger or lesser degree. In order to do this rather than that, I am involved in going for this rather than that. And here we are led to an observation that the majority of cases of decision-making about the future are affectively-related. What I don't know yet is the exact nature of the divide between a however-affectively-motivated decision and

\footnotetext{
6 This remark is also valid for the domain of affectivity itself. In fact, affective events/episodes rarely, if at all, occur 'in crudo', that is, is as a pure sorrow, pure fear, etc., without any other state interfering or being combined with it in the event/episode. We do treat them 'in abstracto'- similarly to thought and emotion - but one may wonder how much this isolation — of different nature than that we see in chemistry - is possible. In chemistry the isolation of elements is less or more difficult depending on the element. Joy or shame or any other emotion would be better compared to a kind of electron cloud; this is a mental area where joy, shame, or any other emotion's presence is predominant.

7 See also Poli (2010).
} 
a predominantly-affectively-motivated decision. And as long as I don't know this I have trouble determining the exact role of affectivity in anticipation or am left with a banal and non-informative answer: anticipation is as affective as the affective component included within it.

Maybe then I should modify the conditions and imagine a person who will perform a task of the sort to be selected by lot. But is that sufficient? Even if she is indifferent to what she will do, she is not, I suppose, entirely indifferent to being involved in a task that will be selected by lot, for she has agreed to go for this instead of refusing it. Maybe then a much simpler example should be given, say, which cup of two (or three or more) I am going to take in order to pour a coffee. Yet, since the topic is anticipation, the task cannot be too simple, or there is will be no anticipation involved. For instance, what kind of anticipation can be related to my taking this or that cup of coffee, if there is no preference whatsoever for either choice?

At this stage it looks as if one of two options is to be accepted: either there is no preference but then there is no anticipation either, let alone an anticipatory move, or if there is anticipation, motivation is at stake as well. With this, the question of what anticipation is and how it is understood arises. For the sake of argument let us say that anticipation occurs if there is the minimum amount of time between a decision and the act being performed. I do not, however, have any idea whether this is correct and, if it is, how we can determine the minimum amount of time.

Because it is difficult to determine this - a quick decision can be devoid of an affective component if it occurs, for example, that the performer is smart enough or, better, technically prepared or equipped through his past experience to correctly choose one of a number of options; and, on the other hand, a slow decision say, taken after several days or weeks, can be still permeated with affectivity ${ }^{8}$ - I suggest taking another path and distinguishing affective and non-affective components as follows: affectivity relates to spontaneity, understood as a position in which I am unable to provide (sufficient and acceptable) reason/s for doing such and such at the moment of doing such and such, whereas non-affective relates to calculation, that is, to a position in which I am able at any time to explain why I am doing such and such. In the case of anticipation, the time would mean the whole time between the decision made to set a plan and the anticipatory action being performed, until its very end.

If this is acceptable, there are two kinds or types of anticipation:

1. Non-affective anticipation occurs when the process between decision-making and the act performed is explainable by a performer at any moment;

2. affective anticipation occurs when the process between decision-making and the act performed is not explainable by a performer during the process at any moment.

And, to complete the picture: mixed anticipation could be added, which occurs if the act performed is explainable only partly.

\footnotetext{
${ }^{8}$ For discussion see Zaborowski (2010).
} 
However, this distinction is not operational, as another issue arises. While this works for non-affective anticipation, it does not work so well for affective anticipation. Non-affective anticipation is a case in which the process between a decision-making and the act performed is explainable by a performer at any moment, and works the other way around too. Given that a process between decision-making and the act performed is explainable by a performer at any moment, it can be considered non-affective. But this is not so for an affective anticipation. Here, if the process between a decision-making and the act performed is not explainable by a performer during the process at any moment, this doesn't mean that an ability to explain is always related to the affective character of anticipation. First, it can be unexplainable, even if not affective, because the performer does not have sufficient and relevant knowledge or because he is not self-reflective. And second, 'unable to explain at any moment' doesn't amount to 'unable to explain at all moments', since it could be too strong a constraint to ask for explanation at every single moment. What commonly happens, it seems, is that an explanation can be given at some moments more easily or quickly than at other moments. Hence, this requirement may not work, especially for a long or extremely strong processes.

For instance, think about the following example of the whole process being explainable: I want to take a train, so I go to the railway station. There, I go to the counter and buy a ticket. I also ask about the platform and departure time. I go to the platform, wait for my train, and take it. This looks unproblematic. However, there are two sets of problems. On the one hand, my account is taken out of a larger context, and, on the other, it neglects elements of each particular act. So several questions can be asked and they may not appear easily answerable, e.g. I buy a ticket but why do I pay with this rather than that banknote? Why do I go to this rather than that counter, several counters being free? Why do I put my handbag on my left rather than on my right, etc.? To some questions I can easily give answers, for others I have to think a bit, for others still I have no response at all. Does this mean there is no clear reason for my act that I can give at the moment of performing it in this case? Or is it simply that I ignore it? And if the former, is this because it is affectivity-dependent? It could be that a reason is motivated by other motives, of which all or some are motivated, again, by several others, and so on and so forth.

Since my suggested distinction between affective and non-affective components is between spontaneous and calculated components, this amounts to a distinction between being able and being unable to provide (sufficient and acceptable) reason/s for doing something at the moment of doing it, which fails, such that an uncertainty as to the core distinction reappears. However, if the realms of feeling and thought are hardly distinguishable, this might be for various reasons. They can be difficult to distinguish epistemically or they may be inseparable ontically. If the former, either the distinction is not known but it will be known or, at least, could be known (=is knowable), or, on the other hand, it will never be known, even though there is a distinction between thought and feeling (=is unknowable). Alternatively, they can be inseparable ontically, because they do not exist 'in crudo', ${ }^{9}$ which means that the

\footnotetext{
${ }^{9}$ See Collingwood $(1992,35)$ : "5.61. Feeling as we are actually conscious of it is a field, a here-and-now extended in space and time (4.43), having a focal region and a penumbral region (4.44), but no edge.".
} 
distinction between thought and feeling is non-existent and, a fortiori, unknowable, such that thought and feeling are simply concepts or analytical constructs. In this case there is no point in looking for a distinction between affective and nonaffective anticipation. And if this is so, those who speak about it and use such a distinction as granted and as a reliable basis for a further investigation commit a category mistake.

Before we have certain knowledge about the epistemic versus the ontic thought/ feeling distinction, the issue is difficult to solve and, consequently, speaking about affective anticipation is inappropriate or vague. As long as the question of affective versus non-affective aspects remains open, we are limited to concluding that, generally, feeling and thought are often associated with one another. And the same stands, I am afraid, for so-called rational (non-affective) and irrational (i.e. affective) factors in anticipation. It is better to admit that they cannot be identified as of now (or at all). But maybe there is a way to avoid thinking that the whole issue is untreatable. Let us admit that all cases of anticipation are of mixed affective-cumnon-affective anticipation and point to three kinds of such a mixture, where (1) the first contains both components more or less equally; (2) the second is predominantly but not exclusively non-affective; and (3) the third is predominantly but not exclusively affective. Given this, each particular occurrence of anticipation belongs to one of the three groups, I recognize that one can know about an occurrence's structure only vaguely and intuitively, at least at first glance.

Examples:

1. There are affective states, say emotions, that are considered cognitive in the sense that they are formed after opinions or beliefs. I do not want to say that all affective states are of such character, nevertheless there are many of this kind. Now, what is missed by supporters of this approach is that there is also a different kind of mental event - in some respects opposed to affective states formed after opinions of beliefs_-such as wishful thinking or prejudices. These are opinions formed after affective states or affective dispositions, moods, etc. I do not want to discuss both kinds. I suspect that with a sufficiently strong pressure from both sides (i.e. cognitivist and anti-cognitivist) we would arrive at the chicken-and-egg dilemma. Let say that they are mixed and this is why I take all of them to contain thought and feeling.

2. The standard example of calculation devoid of an affective component is a calculation as it occurs in mathematics. Let us admit this. (From (1) it can be inferred that a person making a calculation is not devoid of affective process. This is especially visible when the operation turns out to be difficult and requires more and more time and effort. We see, then, how quickly she is dragged, so to speak, into the affective space).

3. To continue the last example, think about the same person now experiencing anger because she is failing in her calculation. The mathematical operations are stopped and she becomes a victim of her increasing anger because, say, she is participating in a game show and loses a competition as well as her status as a skilled mathematician in her country (which she enjoys-otherwise, if she is 
indifferent, for example, there is no point in affectivity whatsoever). I am inclined to consider this case as an example of full affectivity.

There is a final example that can help us. However, in this example another distinction can be drawn, i.e. between (1) my being (so and so) and shaping (my) future unwillingly, and (2) my acting in such and such a way and shaping my future willingly. Unwillingly means that even if I don't want to or am not aware of it, my being such a way, say, having my gait, which may be liked by some and disliked by others, shapes what is going to happen to me. Willingly means I act persistently in order to obtain such and such a result.

But to make things simpler I will omit this distinction and treat this, after Roberto Poli, as a full-fledged anticipation. As he says, it is not the fact that I have got information about coming rain but only the act of taking an umbrella with me that counts. ${ }^{10}$ Following Poli's suggestion, I call (only) the former, i.e. my wish to avoid getting wet if it rains, determination, and the latter, i.e. my taking an umbrella, anticipation. But, here again, a question arises as to whether we can separate both meanings and have in front of us only the latter, namely pure anticipation without determination, as in the case given by Roberto Poli: is my talking umbrella not determined in some way or another by my being so and so? Imagine that I don't take an umbrella, while you take one, but in both cases this is determined or predetermined by several factors, among others by my engagement with the world. How I am engaged with the world is, I suppose, partly pre-determined and partly anticipated by myself. It manifests interest or concern, which is productive of my doing anything at all instead of remaining at equal distance from two bales of hay, so to speak. ${ }^{11}$ For instance, if I watch a film or, better, a football match and no team is my favourite, watching the match hardly produces any emotion, while if one of the two teams is my favourite, I am engaged and, thereby, several emotions are brought about.

The above implies that the issue of affective anticipation reveals the entanglement that characterises human acts. They form a chain, probably impossible to treat, if we consider the great number of links. It looks as if only segment/s of the link can be treated 'in abstracto'. To what extent this deforms the nature of the link analysed cannot be identified here. For this reason, this paper is rather tentative and preparatory for further analysis. More introductory than I wished, it certainly points to an interweaving within anticipation as well as to anticipation as itself being anticipated. Some preliminary matters have been articulated, whereas the lack of sufficient category distinctions is due partly to categorical confusion within affectivity research. One can easily get informed, for instance, by taking a look at the International Society for Research on Emotion (ISRE) forum, where very

\footnotetext{
${ }^{10}$ In his opening paper at the 1 st International Conference on Anticipation, Trento, Nov. 5-7, 2015. I suppose that this approach rules out the following ambiguity: if I want to obtain $\mathrm{X}$ but for several reasons, say lack of knowledge or clumsiness, I obtain $\mathrm{Y}$ or, more generally, not-X, is this or is this not anticipation? And would this mean that anticipation is to be considered only if I am acting and I am successful? With Poli's description we get rid of such dilemmas.

11 See Peirce $(1868,154)$ : "Everything in which we take the least interest creates in us its own particular emotion, however slight this may be.".
} 
recently the following message was posted: "The first thing I noticed was that after all the years together in ISRE, how divergent we still are". ${ }^{12}$

If there is any conclusion to be drawn from the above, it would be that:

1. It is hard to delimit and identify a purely affective anticipation (the same for a purely non-affective anticipation).

2. This is why it is better to take anticipation as being mixed, i.e. including both affective and non-affective components.

3. However, if one thinks that any thing we do, we do out of interest, out of an engagement, then it can be said that an affective component is (always) prior to any other-other affective component/s as well as a non-affective component/s - and that it underlies the anticipatory move.

Now, limiting anticipation constitution to its affective component alone, I am tempted to ask: Are all affective phenomena equally relevant? Are kinds of anticipation as numerous as kinds of affectivity, including their mixtures? I think it could reasonably be said that sensible, or bodily, if you prefer, feelings are less anticipatory than psychic or spiritual feelings. While what Scheler calls vital feelings - feelings related to the whole body-anticipate the value of (possible) stimuli, pointing to the value of what is coming, ${ }^{13}$ spiritual feelings are related to the value of the person and as such they anticipate her actions at a more general and long-lasting level. (Surely, some sceptics could also argue that anticipation pointing to the value of bodily stimuli would turn out to be more laden with consequences than an anticipation pointing to, say, the value of cultural items and the so-called meaning of life.) Accordingly, vital feelings inform a person about her bodily condition and, consequently, are anticipatory at this level, i.e. at the level of body functioning, whereas spiritual feelings refer to quite a different realm, both in informing and anticipating-which is, so to speak, her being or not being. I am reminded of Achilles, who had been informed several times about the issue of his acts, or Socrates, who maybe not have received such a warning and whose case may seem to be less affectivity-related-yet he pursued his actions till the very end and he maintained his decision while in prison, even though he was offered freedom.

But what about modi of affectivity? Are all groups of feelings equally anticipatory? Commonly, fear is considered to be a typically anticipatory feeling, and anger is also often given as example of this type. ${ }^{14}$ According to Hartmann, ${ }^{15}$ of

\footnotetext{
12 By Tom Scheff, on Apr. 29, 2016 (http://lists.psu.edu/cgi-bin/wa?A2=ind1604\&L=ISRE-L\&F=\&S= $\& \mathrm{P}=18302$, retrieved on Apr. 30, 2016). The discussion was launched by his message on Apr. 18, 2016, with an initial query: "Does anyone know of attempts to define basic emotions operationally (rather than just using the vernacular terms, or only conceptually? Such as grief, fear, anger, shame, pride, guilt?" (http://lists.psu.edu/cgi-bin/wa?A2=ind1604\&L=ISRE-L\&F=\&S=\&P=2284, retrieved Apr. 30, 2016).

13 See Scheler 1973, 341.

14 See Martinho and Paiva (2008, 117): "One of the principal functions ascribed to emotions is precisely that of anticipating events, especially when such events are relevant to the central concern of the organism [...] I "feel" afraid and ready to run away [...]". Moreover, they remark, "[...] the anticipation of an event may also elicit an emotion. Continuing our example... To avoid the "frightening creature", I decide to $[\ldots]$ "...

15 See Hartmann 1931, 16-20 and Hartmann 1965, 163-184.
} 
the three groups, (1) emotional and receptive acts ("rezeptive Akte"), (2) emotional and prospective acts ("emotional-antizipierenden Akte"), and (3) emotional and spontaneous acts ("Aktivität oder Spontaneität"), only the second is explicitly called "anticipatory". It is about "expecting, foreseeing, foreboding, being anxious, hoping, desiring". Acts relating to the present moment (e.g. "living through, enduring our fate, enduring the harsh reality") have no anticipatory character as do, similarly, acts of the third group, though they are aimed at the future. ${ }^{16}$ This suggests that there are affective acts that have nothing to do with anticipation. ${ }^{17}$ Such seems to be the case for joy and sorrow. They are often non-motivational and, thereby, unproductive. For instance, in Aquinas' view:

[...] in the movements of the appetitive faculty, good has, as it were, a force of attraction, while evil has a force of repulsion. [...] when the good is obtained, it causes the appetite to rest, as it were, in the good obtained: and this belongs to the passion of "delight" or "joy"; the contrary of which, in respect of evil, is "sorrow" or "sadness." (Thomas Aquinas 1947, 1a2æ 23.4.)

This distinction is of interest here, since we come across emotions of motion ('motus') and emotions of rest ('quietatio'), and only the former are directed to what is absent, that is, so to speak, to what exists in the future, while the latter relate to what is present with no anticipatory element. But is it really so? Or should we rather speak about foreground and background anticipation? One anticipates one's future by doing such and such and, less visibly, by being so and so. In this sense being in a state of joy or sorrow contributes to one's being more or less optimistic or less or more pessimistic which, in turn, anticipates one's approach to reality, one's future included. Read this way, optimism and pessimism are two general ways of anticipating an approach to reality. They are contrasted, respectively, by an opening and a closure of possibilities in grasping the future. Even if unconsciously, openness and refusal contribute differently to a view of reality, either as welcoming or hostile. In both cases anticipation almost becomes a mechanism, a kind of self-fulfilling prophecy.

\section{A Short Conclusion}

If we agree that there is an underlying affective component in anticipation, then it would be accurate to say that there is an anticipating anticipation of the following form: interest/concern/engagement resulting in anticipation. On the other hand, anticipation is mixed:

\footnotetext{
16 This is because, in contrast to the two others, the third group comprises acts that are active rather than passive. They are teleological in the sense of "interfering in the future" (and not only "waiting for it", as it is characteristic of the second group of acts). It seems that anticipation, for Hartmann, is therefore a passive position.

17 Accordingly, if it is assumed that "emotion [...] is an anticipating or preceding "reaction" (prereaction) of an organism to what is coming to happen" (Wiener 2009, 100), this is too general because some emotions are not reactions in the sense of being directed towards what is going to occur. Similarly in E. Salzen's Thwarted Action State Signalling Theory of Emotion (TASS), not all emotions can be described as "states that occur when activated motivated behaviours are thwarted or in conflict" (Salzen 1991, 51). Again, the example of joy comes to mind.
} 


$$
\begin{gathered}
\text { anticipation } \\
= \\
\text { feeling }+ \text { thought. }
\end{gathered}
$$

To analyse the affective component of the anticipatory move, several distinctions are to be made:

1. levels of affectivity,

2. modi of affectivity,

3. level of affectivity combined with modus of affectivity,

4. maybe some other factor/s.

It goes without saying that to draw a detailed picture of all possible cases is beyond the scope of this paper.

I have distinguished direct anticipation (in cases like anger, fear, etc.) and indirect anticipation (joy or sorrow, which, though not resulting in an anticipatory move, anticipate the general approach to reality, called, respectively, optimism or pessimism). While the former fits with an awareness of my wanting to anticipate, the latter is devoid of this: by being optimistic or pessimistic I anticipate my future though I may not be aware that my being so and so anticipates my future in a such and such a way. And paradoxically, while the former looks active and the latter passive, the latter often envelops my whole life or, at least, a big part of it, while the latter embraces only single episodes. After all, the way of my acting out of a particular anger, fear, shame, etc. may, as a matter of fact, be determined, that is, anticipated by my general approach—such as my optimism, pessimism, etc.

Last not least. Just as affectivity is anticipatory in some cases, so it is anticipated itself in others. ${ }^{18}$ This idea echoes Aristotle's model, in which affectivity is a part of character in two senses: it builds character, and is shaped by character. For instance, I can indirectly control my affectivity by becoming the person I want to become. And becoming such a person means modifying my affectivity. ${ }^{19}$ This is also the approach of Aristotle's Athenian teacher, who distinguishes between anticipated and anticipatory or anticipating pleasures and unpleasures. In the "Philebus" we read:

but he remembers the pleasures the coming of which would bring him an end of his pain; as yet, however, he does not possess them. [...] and often a man sees an abundance of gold coming into his possession, and in its train many pleasures; and he even sees a picture of himself enjoying himself immensely (35e \& 40a, trans. H. N. Fowler).

And also that:

the pleasures and pains which belong to the soul alone might come before the pleasures and pains of the body, so that we have the pleasure and pain of

\footnotetext{
18 This is to say that emotions shape or anticipate behaviours and, on the other hand, behaviours shape/ anticipate emotions - on the latter see Baumeister et al. (2007) and Castelfranchi and Miceli (2011).

19 A circularity has to be recognized here. Yet it is not vicious. See Helm (2010, 313).
} 


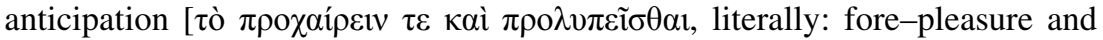
fore-unpleasure], which relate to the future" (39d, trans. H. N. Fowler).

Open Access This article is distributed under the terms of the Creative Commons Attribution 4.0 International License (http://creativecommons.org/licenses/by/4.0/), which permits unrestricted use, distribution, and reproduction in any medium, provided you give appropriate credit to the original author(s) and the source, provide a link to the Creative Commons license, and indicate if changes were made.

\section{References}

Aristotle (1934) Nicomachean ethics (trans: Rackham H). Harvard University Press, William Heinemann Ltd., Cambridge

Baumeister RF, Vohs KD, DeWall CN, Zhang L (2007) How emotion shapes behavior: feedback, anticipation, and reflection, rather than direct causation. Personal Soc Psychol Rev 11(2):167-203

Castelfranchi C, Miceli M (2011) Anticipation and emotion. In: Petta P, Pelachaud C, Cowie R (eds) Emotion-oriented systems. Springer, Heidelberg, pp 483-500

Collingwood RC (1992) New Leviathan: Or Man, Society, Civilization and Barbarism. Clarendon Press, Oxford

Hartmann N (1931) Zum Problem der Realitätsgegebenheit. Pan-Verlagsgesellschaft, Berlin

Hartmann N (1965) Zur Grundlegung der Ontologie. Walter de Gruyter \& Co., Berlin

Heidegger M (1962) Being and time (trans: Macquarrie J, Robinson E). Basil Blackwell, Oxford

Helm BW (2010) Emotions and motivation: reconsidering neo-jamesian accounts. In: Goldie P (ed) The

Oxford Handbook of Philosophy of Emotion. Oxford University Press, Oxford, pp 303-323

Lyons W (1980) Emotion. Cambridge University Press, Cambridge

Martinho C, Paiva A (2008) Anticipation and believability. In: Pezzulo G, Butz MV, Castelfranchi C, Falcone R (eds) The challenge of anticipation. Springer, Heidelberg, pp 115-133

Pascal B (1958) Pensées (trans: Trotter WF). E. P. Dutton \& Co., New York

Peirce CS (1868) Some consequences of four incapacities. J Specul Philos 2(3):140-157

Plato (1925) Philebus (trans: Fowler HN). Harvard University Press, William Heinemann Ltd., Cambridge

Poli R (2010) An introduction to the ontology of anticipation. Futures 42:769-776

Rosen R (1985) Anticipatory systems. Philosophical, mathematical and methodological foundations. Pergamon Press, Oxford

Salzen E (1991) On the nature of emotion. Int J Comp Psychol 5(2):47-88

Scheler M (1973) Formalism in ethics and non-formal ethics of values. A new attempt toward the foundation of an ethical personalism (trans: Frings MS, Funk RL). Northwestern University Press, Evanston

Thomas A (1947) Summa theologica (trans: The Fathers of the English Dominican Province). Benziger Bros., New York

Wiener D (2009) Antycypacja a procesy emocjonalne. Wydawnictwo Naukowe UAM, Poznań

Zaborowski R (2010) On time as a factor differentiating feeling and thought. Aristotle-FortenbaughAntiphon the sophist-Weininger. Organon 42:71-82

Zaborowski R (2015) Plato and Max Scheler on the affective world. Organon 47:65-81 